\title{
PRUNE - BELLY SYNDROME WITH SPINA BIFIDA AND ANORECTAL AGENESIS
}

\author{
Joshi B D*, Prasad R*, Singh R, Bhatta N K*, Bhattarai $S J^{*}$
}

\section{ABSTRACT}

\begin{abstract}
Prune Belly Syndrome is a rare birth defect with only few cases reported in our part. A newborn baby with Prune belly syndrome is presented along with review of literature.
\end{abstract}

\section{Key Words: Prune belly, abdominal muscle, urinary tract anomaly}

\section{INTRODUCTION}

Prune Belly syndrome is an uncommon birth defect seen in 1 in 50,000 live births. ${ }^{1}$ This condition occurs more commonly in males with less than $3 \%$ occurring in female patients and characterized by abdominal musculature deficiency, anomalous development of urinary tract and bilateral cryptorchidism. ${ }^{2}$ We report a case of Prune Belly syndrome with rare association of spina bifida occulta and anorectal agenesis from our institute which is not reported from our part.

\section{CASE SUMMARY}

A newborn male delivered from 26 years old (gravida-two, unbooked, non-immunized) mother by cesarean section and had no respiratory effort after birth. Initial steps of neonatal resuscitation were done and the baby was later kept on IPPV with AMBU bag after endotracheal intubation. The previous sibling, three years old female child is healthy. On examination, the baby had asymmetrical facies, low set and deformed ear, high arched palate, upward slanting of palpebral tissues and right sided hemihypetrophy. The abdominal wall was loose, prominent, wrinkled with visible peristalsis and bulging of flanks. There was also exomphalus, bilaterally undescended testes, hypospadius and absence of anal opening. The palpation of abdomen showed deficiency of abdominal muscles, herniation of bowel loops in parities, hepatomegaly (Liver span: $8 \mathrm{~cm}$ ) and bilaterally palpable kidney. Musculoskeletal evaluation showed bilateral talipes equinovarus with a dermal sinus over back in midline, lumbar region.Cardiovascular examinations were normal. With these clinical findings a diagnosis of Prune Belly syndrome was made.

The baby was later transferred to NICU and put on mechanical ventilation. IMV mode but not able to maintain saturation even on maximum ventilatory settings (PIP:30, PEEP:6.0 and Fio2:100\%). Two hours later, the patient developed cardiac arrest. The cause of death was respiratory failure.

The routine investigation showed $\mathrm{Hb} \%: 16 \mathrm{gm} / \mathrm{dl}$ (Hct:50), TLC 13,500/cumm, and DLC;P:45\% and L:55\%. Blood glucose and serum calcium were normal. Blood urea and serum creatinine at the time of admission were $92 \mathrm{mgldl}$ and $2.1 \mathrm{mg} / \mathrm{dl}$ respectively. X-ray of the baby showed hypoplasia of both lung with eventration of diaphragm and spina bifida at L4 and L5 region of spine. Ultrasonography of abdomen showed deficiency of abdominal muscles with herniation of bowel loops in parities. Right kidney had multiple subcortical cyst suggestive of polycystic disease whereas left kidney was dysplastic. Both pelves were dilated but ureter and bladder were normal. Liver had also multiple cysts. Voiding cystourethrogram and renal scanning could not be done because of early death of the patient.

* Kanti Childrens Hospital, Maharajgunj, Kathmandu, Nepal.

Address for correspondence : Dr. Bharat D. Joshi

Kanti Childrens Hospital, Marajgunj, Kathmandu, Nepal.

Email: joshibharatnp@yahoo.com 


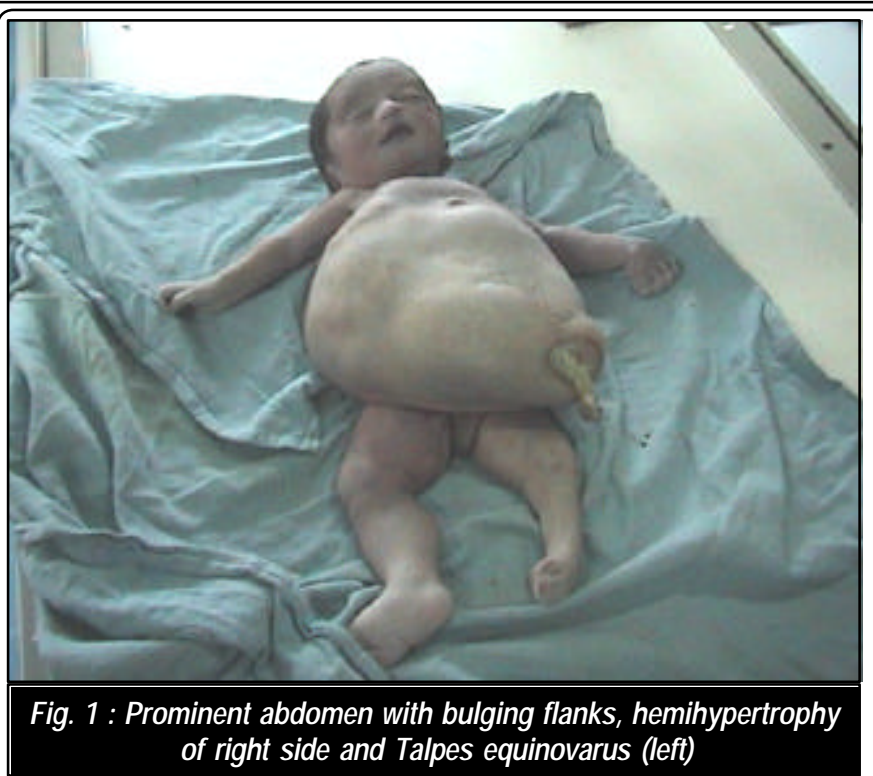

\section{DISCUSSION}

Prune Belly syndrome is an autosomal recessive disease which occurs more commonly in male with less than $3 \%$ cases in female. It occurs in all races. ${ }^{1}$ The exact cause is unknown, however some cases have been reported in siblings, suggesting a genetic component. Two postulated hypothesis of pathogenesis are urinary tract obstruction during fetal development and primary mesodermal defect. ${ }^{3}$ Prune Belly syndrome is characterised by triad of anomalies that include absence or hypoplasia of abdominal muscle, bilateral cryptorchidisn and urinary tract anomalies.

The abdominal musculature defects vary from mild hypoplasia to agenesis of muscular layer of lower and medial aspect of abdomen which is patchy and asymmetrical. The urinary tract abnormalities include widely dilated urethra with urethral stenosis or atresia, hypoplastic prostate, thickened enlarged bladder, patent urachus, hydro or megaloureter and dysplastic, cystic, hypoplastic or hydronephrotic kidneys. Our patient has cystic and dysplastic kidneys and dilated pelves only. The absence of other urinary tract abnormalies in this case may be due to early diagnosis at birth or obstruction of proximal part of ureter. Testicles are usually intra-abdominal as in our patients resulting in azoospermia and infertility in later life. Other manifestations include, pulmonary hypoplasia, lobar atelectasis, cardiovascular abnormalities ie. ASD, PDA, TOF, VSD and gastrointestinal anomalies ie gastrochisis, imperforate anus, malrotation with volvulus. The musculoskeletal defects reported with Prune Belly syndrome are talipes, dislocation of hip joint, diastases of pubis polydactyly and scoliosis. Our patient had also spina bifida occulta which is not reported till date. ${ }^{4}$

Often Prune Belly syndrome is diagnosed by fetal ultrasound while a mother is still pregnant and ultrasound, voiding cystourethrogram and Tc99m DMSA scanning after birth., ${ }^{1,5,6}$ The characteristic findings in USG are diffusely hyerechoic parenchyma, small parenchymal cysts, clubbed dysplastic calyces, markedly tortuous ureters, marked trabeculation of bladder and widened long posterior urethra. The increased echogenicity of parenchyma is an indicator of underlying dysplasia of renal tissue during differentiation and maturation., ${ }^{5,6}$ Our patient had polycystic changes in right and dysplastic changes in left kidney, Antenatal diagnosis by amniocentesis and ultrasonography and vesiculo-amniotic shunt in utero is the most promising therapeutic options in such babies. ${ }^{7}$ Other surgical intervention recommended are vesicostomy, reconstruction of urinary tract and reimplantation of ureters.

The prognosis varies from death in utero or death within a few months to near normal life expectancy depending on the degree of renal dysplasia. The respiratory function abnormalities and exercise intolerance occur at later life due to abdominal muscle deficiency. ${ }^{8}$ Babies are usually born limp and blue needing all resuscitative measures .Many are stillborn. Even in level three care neonatal centers mortality ranges between $90-95 \% .^{9}$ The most common cause of death is renal failure and less commonly due to respiratory insufficiency. Our patient had died due to respiratory failure.

\section{CONCLUSION}

Prune Belly syndrome, an autosomal recessive disorder may be diagnosed antenatally by amniocentesis and ultrasonography. Prenatal diagnosis, in utero and ex-utero surgical intervention and effective resuscitation at birth may decrease the mortality of such babies.

\section{REFERENCES}

1 Cronie W. I nd i cati ons of antenatal U trasound screering in the i nci dence of naj or geni touri nary nal fornati ons. Sennn Ped atr Surg 2001; 10 (4): 204-11.

2 Eagl e JF, Barret $G$. congeni tal def $\mathrm{i}$ ci ency of abdonnnal noscul ature with associ ated geri touri nary abnornal iti es, a syndrone. Pedi atrics 1950, 6: 721

3 Wheatl ey J M Stephens FD Hitson J M Prune bel I y syndrone: ongoi ng cont roversi es regardi ng pathogenesi s and managenent. Senin Ped atr. Surg. 1996; 5(2): 95-106.

4 Sutherl and RS, Nevorach RA Logan BA The prune bel Iy syndrone current insight. Ped atr Nepdrd 1995; 96): $70-78$.

5 Kafer M, Peters $C A$ Petik AB, Benacerraf BB I ncreesed rend echogeri ci ty. a sonographi c si gn for d fferenti ati ing between dbstructi ve and non dbstructi ve etid og es of in utero bladder di stensi on J urd 1997; 158(3): 1026-29.

6 Gaglianti i P, Naradiano G R cd M, L icata G The Prune bd Iy syndrone: an unusual case Rad d Nad 2001; 101(1-2): 85-87.

7. Leeners B, Sauer I, cotarel o A Prune bel ly syndrone. therapeuti c opti ons i ncl udi ng in utero pl acenent of vesi coanni oti c shunt. J G in u trasound 2000, 28: 500-507.

8 Noh PH Cooper CS, W/rker AC Prognostic factors for I ong term rend function in boys with the prune bel ly syndrone J Utd 1999; 162(4): 1399- 401.

9 R Singh Prune-Bd ly Syndrone -a case report. J. Nep Nad AssoC 1998; 37: 449-50.

$$
\text { 25 es es }
$$

